\title{
Detection of Toxoplasma gondii in chicken and soil of chicken farms in Nanjing region, China
}

Xin-Chao Liu, Yu He, Deng-Ge Han, Zhen-Chao Zhang, Ke Li, Shuai Wang, Li-Xin Xu, Ruo-Feng Yan and Xiang-Rui Li

\begin{abstract}
Background: Soil is increasingly recognized as an important source in the transmission of Toxoplasma gondii (T. gondii). The aim of this study was to investigate the presence of T. gondii in the soil and to grasp the relationships between the contamination of soil and chicken infections.

Methods: PCR method based on T. gondii-conserved gene internal transcribed spacer 1 (ITS-1) as target gene and ELISA method (sGRA8-ELISA) using the recombinant protein of shortened GRA8 gene of T. gondii as antigen were developed and applied. From April 2013 to March 2014, a total of 700 soil samples were collected at various sites located in thirty farms categorized as free range farm and scale farm in Nanjing, Jiangsu, China, in different seasons. Additionally, a total of 350 sera of chickens were collected from free range farms to determine the presence of antibodies against $T$. gondii using SGRA8-ELISA.

Results: The serological results showed that, antibodies were found in 194 of 250 (67.14\%) samples from farms with $T$. gondii positive in soil and 41 of 100 samples from farms with $T$. gondii negative in soil $(41.00 \%)(P<0.01)$. The PCR detection of soil samples showed that, 7 (2.0\%) of 350 samples collected from feeding zone in free range farms were found positive of T. gondii, whereas no sample was positive in scale farms. In the seasonal detections, T. gondii was found in 6 (3.33\%) samples collected in autumn and $1(0.56 \%)$ collected in winter.

Conclusions: The results indicated that the contamination of $T$. gondii in soil in the free range farms was higher than that in the scale farms and seroprevalence of $T$. gondii in chickens in the farm with soil contamination was higher than that with no soil contamination. The soil contamination might be an effective indicator of $T$. gondii infection in chickens.
\end{abstract}

Keyword: Toxoplasma gondii, Chickens farms, Soil, Chicken

\section{Multilingual abstracts}

Please see Additional file 1 for translations of the abstract into the five official working languages of the United Nations.

\section{Background}

Toxoplasmosis is a zoonotic disease caused by the obligate intracellular parasite $T$. gondii. Toxoplasmosis can cause severe neurologic, ocular, and systemic diseases in neonates and individuals with weakened immune system [1]. T. gondii infections are widely prevalent in human

\footnotetext{
* Correspondence: lixiangrui@njau.edu.cn

College of Veterinary Medicine, Nanjing Agricultural University, Nanjing, Jiangsu 210095, People's Republic of China
}

beings and animals worldwide [2, 3]. In China, many investigations have been done to estimate the prevalence of T. gondii infection in swine [4], poultry [5] and in the shellfish and fish [6]. It has been accepted that postnatal infections in humans are acquired by ingesting one of the two persistent stages of $T$. gondii, i.e. tissue cysts in meat or viscera of many animals and oocysts [7]. It was estimated that Toxoplasma caused $8 \%$ of hospitalizations and $24 \%$ of deaths resulting from foodborne illnesses in the United States [8]. So far no foodborne toxoplasmosis has been reported in China. But findings from recent studies indicate that $T$. gondii encysts in muscle more efficiently than in the brain [2], making chicken, one of 
the main meat source in China, a potentially significant source of infection.

The result of serological surveys in China indicates a high prevalence of infection in chickens $[5,9]$. In our laboratory, a total of 1173 free range chicken serum samples from 13 provinces/municipalities were tested for T. gondii circulating antigens (TCA) and antibodies (TCAb), respectively. The results showed that 199 (16.97\%) were positive for TCA, 226 (19.27\%) were positive for TCAb, 69 (5.88\%) were positive for both TCA and TCAb, and the total seropositive rate was found in $356(30.35 \%)$ out of 1173 samples. Although it was lower than that of other reports [10-12], all of the detected provinces were found of positive samples of $T$. gondii [13]. In brief, $T$. gondii in chickens is a large threat to poultry industry as well as chickens consumers.

The oocysts of $T$. gondii are produced by its final host, the domestic cat or wild felines [2, 14]. Cats can excrete millions of oocysts into soil after ingesting only one bradyzoite or one tissue cyst, and the sporulated oocysts of $T$. gondii can remain infective in soils for 18 months under various temperatures [15]. So soil is a major source of infection of T. gondii for both animals and humans.

Until now, a few studies have been conducted worldwide to determine the status of soil contamination with $T$. gondii by molecular methods $[16,17]$. And the results indicated that the soils from gardens [18], pig farms [19], public schools [20] and public parks [21] were all contaminated with $T$. gondii oocysts in a large numbers. However, there were no reports about the soil contamination of $T$. gondii oocysts in chicken farms in China. So in this study, soil contamination with $T$. gondii in different types of chicken farms in China were investigated using PCR method and the relationship between the status of soil contamination and the infection of $T$. gondii in chickens were evaluated using the established ELISA method.

\section{Methods}

The parasites

T. gondii strain RH (type I) used in the present study is virulent strain for mice. The strain $\mathrm{RH}$ of human origin was stored in liquid nitrogen in the Laboratory of Veterinary Molecular and Immunological Parasitology, Nanjing Agricultural University, P.R. China. Initially, the strain was maintained by intraperitoneal passage (twice weekly) in mice. Tachyzoites were then obtained from peritoneal washings in mice inoculated. The tachyzoites were washed by centrifugation using phosphate buffered saline (PBS) and were finally resuspended in PBS.

\section{Establishment of the ELISA method Serum samples}

A total of 50 broiler chickens (Gallus domesticus) were obtained from a commercial farm in Nanjing City of
Jiangsu Province, P. R. China. Twenty chickens at 14 days old were infected intraperitoneally with tachyzoites $\left(10^{7}\right)$ of $\mathrm{RH}$ strain of $T$. gondii and the sera were obtained from hearts at $7,14,21,28,45,60,75,90,130$ days post-infection(DPI). The negative sera were obtained from the other 30 blank chickens at 14 days old. According to Yanming Sun' report, the standard sGRA8 positive serum was generated [22]. Finally, the serum was collected and stored at $-20{ }^{\circ} \mathrm{C}$ until use [22].

The serum against 7 Eimeria coccidian strains (Eimeria. tenella, Eimeria.maxima, Eimeria.mitis, Eimeria.acervulina, Eimeria.praecox, Eimeria.necatrix, Eimeria.brunetti) were stored in our laboratory. Serum against newcastle disease virus (NDV) and infectious bursal disease virus (IBDV) were graciously provided by professor $\mathrm{Li}$ yin and Wang yongshan, institute of Veterinary Research, Jiangsu Academy of Agricultural Sciences, PR China. The Escherichia coli infected chicken serum was gifted from professor Wang chuanqing, Henan Agricultural University, PR China.

\section{sGRA8-ELISA method}

The sGRA8 protein was stored in our laboratory. Sera diluted at 1:10 were added to 96-well polystyrene microstate ELISA plates coated with $0.1 \mathrm{~mL}(170 \mathrm{ng})$ of the sGRA8 antigen and incubated for $2 \mathrm{~h}$ at $37{ }^{\circ} \mathrm{C}$. The plates were then washed three times with $0.1 \mathrm{~mL}$ phosphate-buffer-saline-Tween (PBST) and diluted horseradish peroxidase (HRP)-conjugated goat antichicken IgG (Sigma) (1:6 000) was added. Peroxidase activity was revealed by adding $0.1 \mathrm{~mL}$ of tetramethylbenzidine (TMB) substrate buffer solution for $10 \mathrm{~min}$ at room temperature. The reaction was then stopped immediately and OD value was measured at $450 \mathrm{~nm}$ using microplate spectrophotometer (Bio-Rad Laboratories, Hercules, CA, USA).

\section{The cut-off between positive and negative serum}

Thirty negative sera were detected by the sGRA8-ELISA, and the cut-off between positive and negative serum was calculated from the average of the sGRA8-negative serum plus 3 standard deviations (SD) of the mean.

$$
\begin{aligned}
& \text { The cut-off = the average of negative serum + 3SD } \\
& \text { Negative control: sample OD } 450<\text { cut-off; } \\
& \text { Positive control: sample OD } 450 \geq \text { cut-off; }
\end{aligned}
$$

\section{Sensitivity and Specificity of the SGRA8-ELISA}

The standard sGRA 8 positive serum was diluted from 1:10 to 1:5 242880 . The ELISA was conducted according to the above method.

According to the method above, the infected sera against 7 strains of Eimeria coccidian, NDV, IBDV and Escherichia Coli were detected by sGRA8-ELISA. 
Meanwhile the standard sGRA8 positive serum and negative serum were detected as controls respectively.

\section{Coincidence rate of sGRA8-ELISA method}

The chickens sera collected from artificial infection with T. gondii from day 7 to day 130 were detected by the method established above. The standard sGRA8 positive serum and negative serum were detected simultaneously.

\section{Development of PCR method for soil detection}

The PCR method based on T. gondii-conserved gene internal transcribed spacer 1 (ITS-1) as target gene for soil detection was conducted according to previously reported [6]. To standardize the sensitivity, diluted T. gondii tachyzoites at the concentration of $1 \times 10^{5}, 1 \times 10^{4}$, $1 \times 10^{3}, 5 \times 10^{2}, 1 \times 10^{2}, 5 \times 10^{1}, 1 \times 10^{1}, 1 \times 10^{0}$ were mixed respectively with $0.5 \mathrm{~g}$ blank soils. The negative control with only blank soil was set. Then the total DNA of the mixture and negative control were extracted by the commercial E.Z.N.A TM Soil DNA Kit (OMEGA, USA) according to the manufacturer's instructions and was used as template for the PCR.

The PCR products were then loaded onto $1 \%$ agarose gels (Sigma-Aldrich, St. Louis, MO, USA). The resulting DNA fragments were visualized by the Gel Doc XR System and analyzed using Quantity One 4.6.3 software (Bio-Rad, Hercules, CA, USA). The size of the amplified PCR products was estimated by comparison with the DL2000 DNA Marker (TaKaRa, Dalian, China).

\section{Collection of soil and chicken samples for detection Soil samples}

From April 2013 to March 2014, 700 soil samples were collected from thirty farms, including 15 free range farms and 15 scale farms, in Nanjing, Jiangsu, China. In free range farms, the facilities were categorized into feeding zone and motion zone. Feeding zone is the rest area or the house for chickens. Motion zone is the distances around the feeding zone for $10 \mathrm{~m}$. Five soil samples were taken from feeding zone and motion zone, respectively at each sampling time, and the total number of soil samples collected in free range farms were 350. In scale farms, no distinction was drawn between feeding zone and motion zone, and at each sampling time 10 soil samples were collected around the water place and coops, whereas 350 samples were collected from scale farms.

Besides that, the 700 soil samples were collected in different seasons. In spring, 160 samples were collected, and 180 samples were collected respectively in summer, autumn and winter. Finally, each of the seven hundred samples taken from the surface layer of the ground was about $10 \mathrm{~g}-15 \mathrm{~g}$, and prepared for further examinations (Table 1).

\section{Serum samples of chicken detected}

The chicken from five free range farms with positive soil samples and 2 with negative soil samples were selected to collect serum samples. In each farm, 50 blood samples were collected randomly. Serum was separated from the collected blood by centrifugation at $5000 \times \mathrm{g}$ for $5 \mathrm{~min}$ and stored at $-20{ }^{\circ} \mathrm{C}$ until analysis.

\section{Detection of samples \\ Detection of T. gondii in soil samples by PCR method}

All the 700 soil samples were detected by the PCR method established above. Positive amplicons produced in the detection were purified and sequenced using the ABI 377 automated DNA sequencer (BigDye TerminatorChemistry) employing the same primers as used in the PCR assay to confirm the identity of the products by Shanghai Invitrogen Biotech (Shanghai, China).

\section{Detection of T. gondii in chickens by ELISA}

Serum samples were detected by sGRA8-ELISA developed above together with the standard sGRA 8 positive serum and negative serum.

\section{Results}

The establishment of the methods

The cut-off between positive and negative serum of IgG level of sGRA8-ELISA method

The average OD450 of negative sera was 0.206 and the standard deviation (SD) was 0.028. So the cut-off was 0.290 . If sample OD $450 \geq 0.290$, it was determined as positive. If sample OD $450<0.290$, it was determined as negative.

\section{The sensitivity and specificity of sGRA8-ELISA method}

In the ELISA sensitivity experiment, the standard sGRA8 positive serum diluted to $1: 81920$ was still detected as positive.

In the ELISA specificity experiment, only standard sGRA8 positive serum presented positive OD value. No positive OD value was observed in any control serum samples.

\section{The coincidence rate of sGRA8-ELISA method}

The result obtained from the detection showed that within 45 days after infection the coincidence rate of sGRA8-ELISA was $100 \%$, and until to the 130th day the coincidence rate reduced to $80 \%$. The detail results were indicated in Table 2.

\section{The sensitivity of PCR method}

Positive products were found in all dilutions except $1 \times 10^{1}$ and $1 \times 10^{0}$ of $T$. gondii tachyzoites in $0.5 \mathrm{~g}$ soil (Fig. 1). The DNA sequence analysis indicated 
Table 1 Detection of Toxoplasma gondii in soil samples

\begin{tabular}{|c|c|c|c|c|c|}
\hline $\begin{array}{l}\text { The time of } \\
\text { collected }\end{array}$ & District & $\begin{array}{l}\text { Type of } \\
\text { farms }\end{array}$ & $\begin{array}{l}\text { NO. of } \\
\text { farms }\end{array}$ & $\begin{array}{l}\text { NO.of } \\
\text { samples }\end{array}$ & $\begin{array}{l}\text { Positive } \\
\text { number }\end{array}$ \\
\hline \multirow[t]{8}{*}{2013.04} & \multirow[t]{2}{*}{ Liuhe } & Free range & 1 & 10 & 0 \\
\hline & & Scale & 1 & 10 & 0 \\
\hline & \multirow[t]{2}{*}{ Jiangning } & Free range & 1 & 10 & 0 \\
\hline & & Scale & 1 & 10 & 0 \\
\hline & \multirow[t]{2}{*}{ Pukou } & Free range & 1 & 10 & 0 \\
\hline & & Scale & 1 & 10 & 0 \\
\hline & \multirow[t]{2}{*}{ Lishui } & Free range & 1 & 10 & 0 \\
\hline & & Scale & 1 & 10 & 0 \\
\hline \multirow[t]{4}{*}{2013.05} & \multirow[t]{2}{*}{ Liuhe } & Free range & 1 & 10 & 0 \\
\hline & & Scale & 1 & 10 & 0 \\
\hline & \multirow[t]{2}{*}{ Jiangning } & Free range & 1 & 10 & 0 \\
\hline & & Scale & 1 & 10 & 0 \\
\hline \multirow[t]{4}{*}{2013.06} & \multirow[t]{2}{*}{ Liuhe } & Free range & 1 & 10 & 0 \\
\hline & & Scale & 1 & 10 & 0 \\
\hline & \multirow[t]{2}{*}{ Pukou } & Free range & 1 & 10 & 0 \\
\hline & & Scale & 1 & 10 & 0 \\
\hline \multirow[t]{2}{*}{2013.07} & \multirow[t]{2}{*}{ Liuhe } & Free range & 1 & 10 & 0 \\
\hline & & Scale & 1 & 10 & 0 \\
\hline \multirow[t]{10}{*}{2013.08} & \multirow[t]{2}{*}{ Liuhe } & Free range & 1 & 10 & 0 \\
\hline & & Scale & 1 & 10 & 0 \\
\hline & \multirow[t]{2}{*}{ Jiangning } & Free range & 1 & 10 & 0 \\
\hline & & Scale & 1 & 10 & 0 \\
\hline & \multirow[t]{2}{*}{ Pukou } & Free range & 1 & 10 & 0 \\
\hline & & Scale & 1 & 10 & 0 \\
\hline & \multirow[t]{2}{*}{ Lishui } & Free range & 1 & 10 & 0 \\
\hline & & Scale & 1 & 10 & 0 \\
\hline & \multirow[t]{2}{*}{ Gaochun } & Free range & 1 & 10 & 0 \\
\hline & & Scale & 1 & 10 & 0 \\
\hline \multirow[t]{6}{*}{2013.09} & \multirow[t]{2}{*}{ Liuhe } & Free range & 1 & 10 & 0 \\
\hline & & Scale & 1 & 10 & 0 \\
\hline & \multirow[t]{2}{*}{ Gaochun } & Free range & 1 & 10 & 0 \\
\hline & & Scale & 1 & 10 & 0 \\
\hline & \multirow[t]{2}{*}{ Gaochun } & Free range & 1 & 10 & 0 \\
\hline & & Scale & 1 & 10 & 0 \\
\hline \multirow[t]{4}{*}{2013.10} & Liuhe & Free range & 1 & 10 & 0 \\
\hline & & Scale & 1 & 10 & 0 \\
\hline & Jiangning & Free range & 1 & 10 & 0 \\
\hline & & Scale & 1 & 10 & 0 \\
\hline 2013.11 & Liuhe & Free range & 1 & 10 & 2 \\
\hline & & Scale & 1 & 10 & 0 \\
\hline & Pukou & Free range & 1 & 10 & 0 \\
\hline & & Scale & 1 & 10 & 0 \\
\hline & Jiangning & Free range & 1 & 10 & 0 \\
\hline & & Scale & 1 & 10 & 0 \\
\hline
\end{tabular}

Table 1 Detection of Toxoplasma gondii in soil samples (Continued)

\begin{tabular}{|c|c|c|c|c|c|}
\hline & Lishui & Free range & 1 & 10 & 1 \\
\hline & & Scale & 1 & 10 & 0 \\
\hline & Gaochun & Free range & 1 & 10 & 1 \\
\hline & & Scale & 1 & 10 & 0 \\
\hline \multirow[t]{4}{*}{2013.12} & Liuhe & Free range & 1 & 10 & 1 \\
\hline & & Scale & 1 & 10 & 0 \\
\hline & Pukou & Free range & 1 & 10 & 1 \\
\hline & & Scale & 1 & 10 & 0 \\
\hline \multirow[t]{6}{*}{2014.01} & Liuhe & Free range & 1 & 10 & 0 \\
\hline & & Scale & 1 & 10 & 0 \\
\hline & Pukou & Free range & 1 & 10 & 0 \\
\hline & & Scale & 1 & 10 & 0 \\
\hline & Lishui & Free range & 1 & 10 & 1 \\
\hline & & Scale & 1 & 10 & 0 \\
\hline \multirow[t]{8}{*}{2014.02} & Liuhe & Free range & 1 & 10 & 0 \\
\hline & & Scale & 1 & 10 & 0 \\
\hline & Pukou & Free range & 1 & 10 & 0 \\
\hline & & Scale & 1 & 10 & 0 \\
\hline & Gaochun & Free range & 1 & 10 & 0 \\
\hline & & Scale & 1 & 10 & 0 \\
\hline & Lishui & Free range & 1 & 10 & 0 \\
\hline & & Scale & 1 & 10 & 0 \\
\hline \multirow[t]{4}{*}{2014.03} & Liuhe & Free range & 1 & 10 & 0 \\
\hline & & Scale & 1 & 10 & 0 \\
\hline & Pukou & Free range & 1 & 10 & 0 \\
\hline & & Scale & 1 & 10 & 0 \\
\hline
\end{tabular}

that the product was consistent with the ITS1sequence of $T$. gondii.

\section{Detection of $T$. gondii in soil samples}

The overall ratio of positive in soil samples

As shown in Table 1, 7 samples (1\%) were detected positive for $T$. gondii by PCR. Sequence analysis showed that the amplicons shared 100 identities with the ITS-1 sequence of the $T$. gondii RH strain (GenBankTM accession number AY259044.1).

\section{Comparison of soil contamination for T. gondii between free range farms and scale farms}

Among 700 samples, 350 were collected from free range farms and scale farms, respectively. Seven (2.0\%) samples were found positive of $T$. gondii DNA in free range farms, whereas no (0\%) sample was positive in scale farms (Table 3 ). The difference was highly significant $(P<0.01)$. 
Table 2 Detection of chicken serum infected with Toxoplasma gondii by sGRA8-ELISA

\begin{tabular}{|c|c|c|c|c|c|c|c|c|c|}
\hline \multirow[t]{2}{*}{ No. } & \multicolumn{9}{|c|}{ The time of blood collection } \\
\hline & $7 d$ & $14 d$ & $21 d$ & $28 d$ & $45 d$ & $60 d$ & $75 d$ & $90 d$ & $130 d$ \\
\hline 1 & 0.582 & 1.432 & 1.206 & 0.806 & 0.576 & 0.577 & 0.735 & 1.583 & 0.184 \\
\hline 2 & 1.303 & 0.913 & 0.706 & 1.278 & 0.546 & 0.444 & 0.189 & 0.837 & 0.447 \\
\hline 3 & 0.372 & 1.125 & 0.427 & 0.953 & 0.736 & 0.230 & 1.132 & 0.574 & 0.190 \\
\hline 4 & 0.882 & 0.548 & 1.099 & 0.766 & 1.021 & 0.326 & 1.340 & 1.008 & 0.256 \\
\hline 5 & 0.335 & 1.300 & 0.622 & 0.566 & 1.004 & 0.504 & 1.313 & 0.122 & 0.346 \\
\hline 6 & 1.534 & 0.429 & 1.293 & 1.366 & 1.015 & 0.339 & 1.367 & 0.346 & 1.082 \\
\hline 7 & 0.783 & 0.354 & 1.502 & 1.588 & 0.779 & 0.682 & 1.566 & 0.406 & 0.171 \\
\hline 8 & 0.876 & 0.815 & 1.206 & 1.602 & 1.108 & 0.561 & 0.254 & 0.226 & 0.706 \\
\hline 9 & 1.129 & 1.534 & 1.146 & 1.043 & 0.954 & 0.931 & 0.727 & 0.344 & 0.329 \\
\hline 10 & 1.603 & 1.064 & 0.905 & 0.843 & 0.928 & 1.312 & 0.699 & 0.391 & 0.311 \\
\hline 11 & 0.860 & 0.554 & 1.079 & 1.008 & 0.330 & 1.202 & 0.852 & 0.816 & 0.307 \\
\hline 12 & 0.669 & 1.106 & 1.099 & 0.852 & 0.220 & 0.370 & 0.810 & 0.837 & 0.298 \\
\hline 13 & 0.517 & 1.069 & 1.147 & 1.561 & 0.835 & 0.996 & 0.868 & 0.519 & 0.372 \\
\hline 14 & 0.536 & 1.156 & 1.082 & 1.056 & 0.902 & 0.551 & 0.831 & 1.234 & 0.542 \\
\hline 15 & 1.084 & 0.879 & 1.321 & 1.140 & 0.768 & 1.123 & 0.744 & 0.415 & 0.602 \\
\hline 16 & 0.900 & 0.871 & 1.743 & 0.420 & 1.058 & 0.502 & 0.801 & 0.662 & 0.560 \\
\hline 17 & 1.373 & 0.619 & 0.722 & 1.266 & 0.867 & 0.900 & 1.571 & 0.285 & 0.851 \\
\hline 18 & .0787 & 1.261 & 0.728 & 1.053 & 0.376 & 0.797 & 1.483 & 1.117 & 0.422 \\
\hline 19 & 0.552 & 1.009 & 1.661 & 1.183 & 0.159 & 1.167 & 1.200 & 0.519 & 0.266 \\
\hline 20 & 0.394 & 1.161 & 1.464 & 1.277 & 0.798 & 1.094 & 0.811 & 0.385 & 0.790 \\
\hline Positive percent & $100 \%$ & $100 \%$ & $100 \%$ & $100 \%$ & $100 \%$ & $95 \%$ & $90 \%$ & $85 \%$ & $80 \%$ \\
\hline
\end{tabular}

Each value in the table was the average of two rapeatition

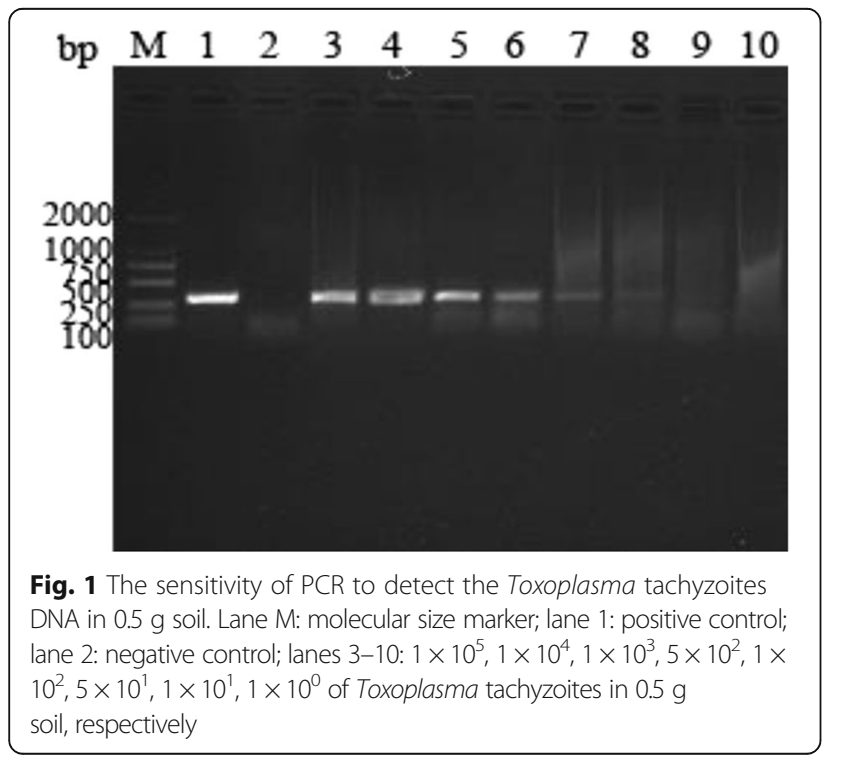

\section{Comparison of soil contamination of T. gondii between feeding zone and motion zone in free range farms}

In free range farms, 175 soil samples were collected respectively from feeding zone and motion zone (Table 3). All of the positive samples (7/175) were from the feeding zone $(P<0.01)$.

\section{Soil contamination status of T. gondii in different seasons}

From spring to summer, no positive sample was found by PCR for $T$. gondii. In autumn, $T$. gondii DNA was found in $6(3.33 \%)$ of 180 samples. Out of the 180 samples collected in winter, $1(0.56 \%)$ sample was detected as positive (Fig. 2).

Table 3 Contamination of T. gondii in the soil collected from different farms

\begin{tabular}{lllll}
\hline Type of farms & $\begin{array}{l}\text { No.of samples } \\
\text { examined }\end{array}$ & $\begin{array}{l}\text { Positive } \\
\text { number }\end{array}$ & PCR positive(\%) \\
\hline Free range farms & Feeding zone & 175 & 7 & 4.00 \\
& motion zone & 175 & 0 & 0 \\
Scale farms & 350 & & 0 & 0 \\
Total & 700 & & 0 & 1.00 \\
\hline
\end{tabular}



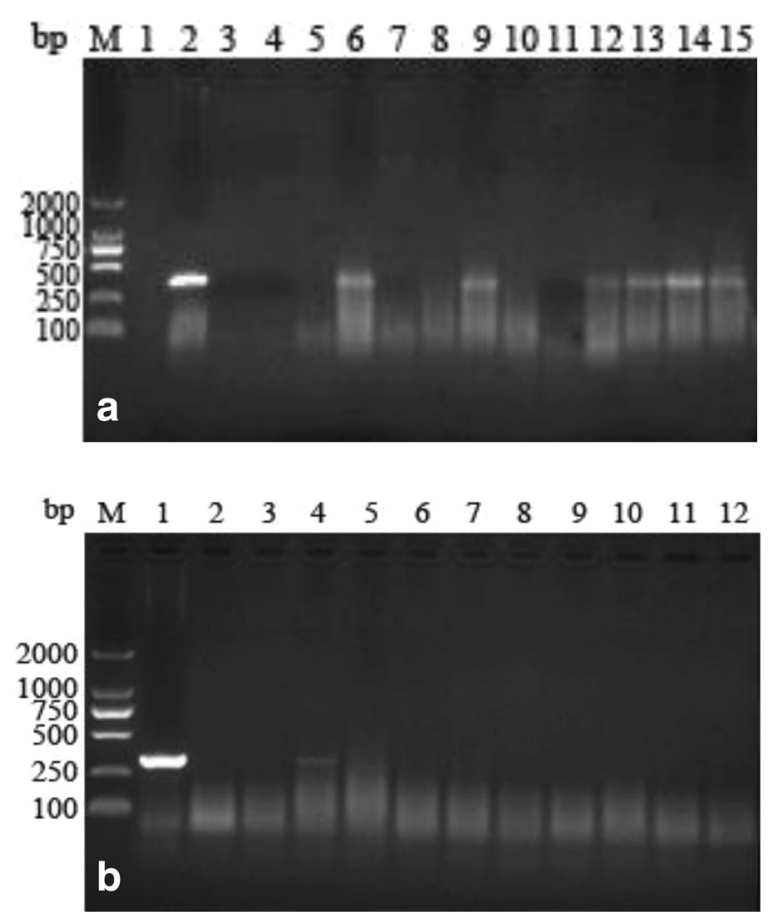

Fig. 2 Detection of T. gondii in soil collected in autumn and in winter. a Lane M: molecular size marker; lane 1: negative control; lane 2: positive control; lanes 3-15: soil samples. b Lane M: molecular size marker; lane 1: positive control; lane 2: negative control; lanes 3-12: soil samples

\section{Detection of $T$. gondii in chickens}

In the 350 chickens detected, total 235 (67.14\%) were seropositive for $T$. gondii. In the 250 chickens from 5 farms with $T$. gondii positive in soil, $77.60 \%$ (194/250) were seropositive. In the 100 chickens from 2 farms with $T$. gondii negative in soil, $41.00 \%$ (41/100) were seropositive. On the farm level, all farms had seropositive chickens.

\section{Discussion}

T. gondii oocysts in environment samples, especially in soils are getting more and more attention. Studies reported that approximately $1 \%$ of cats shed oocysts of $T$. gondii at any given time $[1,23]$ and they excreted oocysts for a median of 8 days with a total of up to 55 million oocysts per day $[1,23]$. The total number of oocysts shed by a single cat varies widely from 3 to 810 million [23]. So it's necessary to establish a sensitive method to detect the soil contamination status of $T$. gondii. The results from previous studies indicated that PCR methods were expected to be highly specific and to be more efficient to detect low oocyst concentrations [24]. Therefore, in this study PCR assay based on the ITS-1 gene was used to detect $T$. gondii oocysts in soil samples for its high specificity and sensitivity [6]. The results of the current research showed that the detection limit of the method was 50 tachyzoites (equal to 6.25 oocysts) [25] of $T$. gondii in $0.5 \mathrm{~g}$ soil. A method previously reported could detect 100-1 000 oocysts in 1 g soil [26]. Compared to this, the PCR method based on the ITS-1 gene established in this study was more sensitive and could be used to detect the $T$. gondii in soil.

Recently, many recombinant surface or secreted antigens have been used successfully either alone or in combination for the detection of specific antibodies due to T. gondii infections in humans and animals. A study reported that rGRA7 ELISA showed a high sensitivity and specificity, and rGRA7 can be used as a potential immunogenic antigen for developing immunodiagnostic tools for immunodiagnosis of toxoplasmosis in patients including patients with cancer [27]. GRA8 is a conserved gene of T. gondii. Previous studies introduced GRA8 as a marker of acute infection and showed that IgG and IgM ELISA with recombinant GRA8 as antigen was able to differentiate acute from chronic infection $[28,29]$ and GRA8 ELISA could be used to detect almost all the common strains of $T$. gondii $[30,31]$. In this study, the truncated GRA8 ELISA method showed that the sGRA8 ELISA could detect specific antibody in all of 20 chickens infected with $T$. gondii 45 DPI, and 95\% 60 DPI. The positive rate was still $80 \% 130 \mathrm{DPI}$. The serum against common infectious diseases of chicken did not present any cross reactions with this antigen. In the sensitivity experiment, the standard sGRA8 positive serum was diluted to 1: 81 920. These results showed that sGRA8 was validated as a useful antigen and promised a highly sensitive and specific ELISA.

In the past, few studies have been investigated soil contamination with $T$. gondii in scale farms and most studies were focused on free range chicken farms, specifically about the prevalence of $T$. gondii infection in chickens [32-34]. Until now, data on the soil contamination of $T$. gondii in chicken farms from China were missing. So in our study, we collected samples from both free range farms as well as scale farms, and compared the relationship between the status of soil contamination and the infection of $T$. gondii in chickens. The results showed that only free range farms had soil contamination with $T$. gondii and there was no $T$. gondii detected among the samples collected from scale farms. It indicated that the soil contamination in free range farms was higher than that in scale farms. Our results were consistent with that obtained by Jacobs [35] in US. Moreover, we firstly divided the free range farm into feeding zone and motion zone. It was demonstrated that all positive samples were found in feeding zones. It indicated that the feeding zones were the main contamination regions in the farms.

In our study, the seasonal changes of soil contamination were observed. Our results suggested that the 
T. gondii in soil was different from spring to winter. In the four seasons, $T$. gondii was only found in autumn and winter. It was in accord with Dubey' study [36], that low temperature contributed to the survival of T.gondii. This indicated that seasons might have important impacts on the presence of $T$. gondii in soil.

In the serum detection, the average serum positive ratio was $67.14 \%$ which was higher than the previously study in our lab (35.15\%) [13]. Furthermore, the seropositive rate for $T$. gondii in farms with $T$. gondii positive in soils was significantly higher than the farms without $T$. gondii in soils. It could be concluded that the infections of $T$. gondii in chickens might be affected by the soil contamination. Thus, the soil contamination of $T$. gondii might be an effective indicator of $T$. gondii infection in chickens.

\section{Conclusion}

In conclusion, the results of the present investigation indicated that high seroprevalence of $T$. gondii in chickens was found in the chicken farms with soil contamination by $T$. gondii. The soil contamination in chicken farms all concentrated in the feeding zone of the free range farms, and was influenced by different seasons. Therefore, monitoring of $T$. gondii in soil, combined with good sanitary practices, should be adopted to prevent $T$. gondii infection in chickens for future.

\section{Additional file}

Additional file 1: Multilingual abstracts in the five official working languages of the United Nations. (PDF 807 kb)

\section{Abbreviations \\ DPI: Days post-infection; IBDV: Bursal disease virus; ITS-1: Internal transcribed spacer 1; NDV: Newcastle disease virus; PBS: Phosphate buffered saline; SD: Standard deviations; T. gondii: Toxoplasma gondii; TCA: T. gondii circulating antigens; TCAb: T. gondii circulating antibodies}

\section{Acknowledgements}

We wish to thank the timely help given by Yin Li and Yong-Shan Wang, institute of Veterinary Research, Jiangsu Academy of Agricultural Sciences, P. R. China and Chuan-Qing Wang, Henan Agricultural University, P. R. China in the sensitivity of the SGRA8-ELISA method study.

\section{Funding}

This work was supported by the Special Fund for Public Welfare Industry of Ministry of Agriculture of China (200903036-04) and the Priority Academic Program Development of Jiangsu Higher Education Institutions, China (PAPD).

\section{Availability of data and materials}

We agree that the data supporting our findings in this study can be found.

\section{Authors' contributions}

XCL developed PCR method for soil detection and drafted the manuscript. $\mathrm{YH}$ carried out the study and participated in the collection of experimental materials. DGH and ZCZ analysed experimental data. KL and SW participated in the establishment of the ELISA method. LXX and RFY helped to draft the manuscript. XRL conceived of the study, and participated in its design and coordination and helped to draft the manuscript. All authors read and approved the final version of the manuscript.

\section{Competing interests}

The authors declare that they have no competing interests.

\section{Consent for publication}

Not applicable.

\section{Ethics approval and consent to participate}

The study was conducted following the guidelines of the Animal Ethics Committee, Nanjing Agricultural University, China. All experimental protocols were approved by the Science and Technology Agency of Jiangsu Province. The approval ID is SYXK (SU) 2010-0005.

Received: 21 September 2016 Accepted: 6 March 2017

Published online: 09 May 2017

\section{References}

1. Dubey JP. Toxoplasmosis of animals and humans. 2010.

2. Dubey JP, Beattie CP. Toxoplasmosis of animals and man. J Parasitol. 1988; 75:816

3. Dubey JP, Su C. Population biology of Toxoplasma gondii: what's out and where did they come from. Mem Inst Oswaldo Cruz. 2009;104:190-5.

4. Wang S, Zhang M, Liu XC, et al. Investigation on the co-infections of Toxoplasma gondii with PRRSV, CSFV or PCV-2 in swine in part of China. J Integr Agric. 2015;14:1838-44.

5. Na Y, Mu MY, Li HK, Miao L, He JB. Seroprevalence of Toxoplasma gondii infection in slaughtered chickens, ducks, and geese in Shenyang, northeastern China. Parasit Vectors. 2012;5:1-4.

6. Zhang M, Yang Z, Wang S, et al. Detection of Toxoplasma gondii in shellfish and fish in parts of China. Vet Parasitol. 2014;200:85-9.

7. Tenter AM. Toxoplasma gondii in animals used for human consumption. Mem Inst Oswaldo Cruz. 2009:104:364-9.

8. Scallan E, Hoekstra RM, Angulo FJ, et al. Foodborne illness acquired in the United States-major pathogens. Emerg Infect Dis. 2011;17:7-15.

9. Xu P, Song X, Wang W, Wang F, Cao L, Liu Q. Seroprevalence of Toxoplasma gondii infection in chickens in Jinzhou, northeastern China. J Parasitol. 2012;98: 1300-1

10. Lindstrom I, Sundar N, Lindh J, et al. Isolation and genotyping of Toxoplasma gondii from Ugandan chickens reveals frequent multiple infections. Parasitology. 2008:135:39-45.

11. Dubey JP, Sundar N, Pineda N, et al. Biologic and genetic characteristics of Toxoplasma gondii isolates in free-range chickens from Nicaragua, Central America. Vet Parasitol. 2006:142:47-53.

12. Dubey JP, Gomez-Marin JE, Bedoya A, et al. Genetic and biologic characteristics of Toxoplasma gondii isolates in free-range chickens from Colombia, South America. Vet Parasitol. 2005;134:67-72.

13. Zhao G, Shen B, Xie Q, et al. Detection of Toxoplasma gondii in free-range chickens in China based on circulating antigens and antibodies. Vet Parasitol. 2012:185:72-7.

14. Frenkel JK, Dubey JP, Miller NL. Toxoplasma gondii in cats: fecal stages identified as coccidian oocysts. Science. 1970;167:893-6.

15. Frenkel JK, Ruiz A, Chinchilla M. Soil survival of toxoplasma oocysts in Kansas and Costa Rica. AmJTrop Med Hyg. 1975;24:439-43.

16. Tavalla M, Oormazdi $H$, Akhlaghi L, et al. Genotyping of Toxoplasma gondii Isolates from Soil Samples in Tehran, Iran. Iran J Parasitol. 2013;8:227-33.

17. Gotteland C, Gilot-Fromont E, Aubert D, et al. Spatial distribution of Toxoplasma gondii oocysts in soil in a rural area: Influence of cats and land use. Vet Parasitol. 2014;205:629-37.

18. Ajmal A, Maqbool A, Qamar MF, Ashraf K, Anjum AA. Detection of Toxoplasma gondii in environmental matrices (water, soil, fruits and vegetables). Afr J Microbiol Res. 2013;7:1505-11.

19. Du F, Zhang Q, Yu Q, Hu M, Zhou Y, Zhao J. Soil contamination of Toxoplasma gondii oocysts in pig farms in central China. Vet Parasitol. 2012;187:53-6.

20. dos Santos TR, Nunes CM, Luvizotto MC, et al. Detection of Toxoplasma gondii oocysts in environmental samples from public schools. Vet Parasitol. 2010;171:53-7.

21. Du F, Feng HL, Nie H, et al. Survey on the contamination of Toxoplasma gondii oocysts in the soil of public parks of Wuhan, China. Vet Parasitol. 2012:184:141-6.

22. Yanming S, Ruofeng Y, Muleke Cl, Guangwei Z, Lixin X, Xiangrui L. Vaccination of goats with recombinant galectin antigen induces partial protection against Haemonchus contortus infection. Parasite Immunol. 2007;29:319-26. 
23. Dabritz HA, Conrad PA. Cats and Toxoplasma: implications for public health. Zoonoses Public Health. 2010;57:34-52.

24. Dumetre A, Darde ML. How to detect Toxoplasma gondii oocysts in environmental samples? FEMS Microbiol Rev. 2003;27:651-61.

25. Speer CA, Clark S, Dubey JP. Ultrastructure of the oocysts, sporocysts, and sporozoites of Toxoplasma gondii. J Parasitol. 1998;84:505-12.

26. Afonso $E$, Lemoine M, Poulle ML, et al. Spatial distribution of soil contamination by Toxoplasma gondii in relation to cat defecation behaviour in an urban area. Int J Parasitol. 2008;38:1017-23.

27. Arabmazar Z, Fallahi S, Koochaki A, Haghighi A, Seyyed Tabaei SJ. Immunodiagnosis and molecular validation of Toxoplasma gondiirecombinant dense granular (GRA) 7 protein for the detection of toxoplasmosis in patients with cancer. Microbiol Res. 2016;183:53-9.

28. Aubert D, Maine GT, Villena I, et al. Recombinant antigens to detect Toxoplasma gondii-specific immunoglobulin $\mathrm{G}$ and immunoglobulin $\mathrm{M}$ in human sera by enzyme immunoassay. J Clin Microbiol. 2000;38:1144-50.

29. Pfrepper Kl, Enders G, Gohl M, et al. Seroreactivity to and avidity for recombinant antigens in toxoplasmosis. Clin Diagn Lab Immunol. 2005;12:977-82.

30. Babaie J, Miri M, Sadeghiani G, Zare M, Khalili G, Golkar M. Expression and Single-step Purification of GRA8 Antigen of Toxoplasma gondii in Escherichia coli. Avicenna J Med Biotechnol. 2011;3:67-77.

31. Koethe M, Pott S, Ludewig M, et al. Prevalence of specific lgG-antibodies against Toxoplasma gondii in domestic turkeys determined by kinetic ELISA based on recombinant GRA7 and GRA8. Vet Parasitol. 2011;180:179-90.

32. Dubey JP, Webb DM, Sundar N, et al. Endemic avian toxoplasmosis on a farm in Illinois: clinical disease, diagnosis, biologic and genetic characteristics of Toxoplasma gondii isolates from chickens (Gallus domesticus), and a goose (Anser anser). Vet Parasitol. 2007;148:207-12.

33. Dubey JP, Sundar N, Gennari SM, et al. Biologic and genetic comparison of Toxoplasma gondii isolates in free-range chickens from the northern Para state and the southern state Rio Grande do Sul, Brazil revealed highly diverse and distinct parasite populations. Vet Parasitol. 2007;143:182-8.

34. Dubey JP, Huong LT, Lawson BW, et al. Seroprevalence and isolation of Toxoplasma gondii from free-range chickens in Ghana, Indonesia, Italy, Poland, and Vietnam. J Parasitol. 2008;94:68-71.

35. Jacobs L, Melton ML. Toxoplasmosis in chickens. J Parasitol. 1966;52:1158-62.

36. Dubey JP. Toxoplasma gondii oocyst survival under defined temperatures. J Parasitol. 1998;84:862-5.

\section{Submit your next manuscript to BioMed Central and we will help you at every step:}

- We accept pre-submission inquiries

- Our selector tool helps you to find the most relevant journal

- We provide round the clock customer support

- Convenient online submission

- Thorough peer review

- Inclusion in PubMed and all major indexing services

- Maximum visibility for your research

Submit your manuscript at www.biomedcentral.com/submit

Biomed Central 